\title{
Comparative In Vitro Quality Evaluation of Some Clopidogrel Tablets, Commercially Available in Bangladesh Drug Market
}

\author{
Lovely Z1 ${ }^{1}$, Abdul A1, Sanjida $\mathrm{H}^{2}$, Sabrin $\mathrm{IK}^{3}$, Sharmeen $\mathrm{A}^{4}$ and Kanij \\ $\mathrm{ND}^{1 *}$ \\ 1Department of Pharmacy, University of Asia Pacific, Dhaka - 1215, Bangladesh \\ 2Department of Pharmacy, ASA University of Bangladesh, Dhaka-1207, Bangladesh \\ ${ }^{3}$ Department of Pharmacy, Southeast University, Banani, Dhaka-1213, Bangladesh \\ ${ }^{4}$ Department of Pharmacy, State University of Bangladesh, Dhaka - 1205, Bangladesh
}

*Corresponding author: Kanij Nahar Deepa, Assistant Professor, Department of Pharmacy, University of Asia Pacific, 74/A Green Road, Farm gate, Dhaka-1215, Bangladesh, Tel: +880-2-58157096, Ext: 411; E-mail: kanijdeepa@uap-bd.edu

\section{Abstract}

Clopidogrel is a potent anti-platelets and antithrombotic drug. It is film coated and $75 \mathrm{mg}$ tablet. The objective of our study was to evaluate the quality parameters of some marketed clopidrogel tablet and to compare the parameters among them. To assess the quality, nine different marketed clopidogrel $75 \mathrm{mg}$ tablet were selected and in-vitro dissolution test, potency, disintegration time were carried out. Other general quality parameters of these tablets like weight variation, hardness, friability were also determined according to established protocols. All the brands comply the requirements of "United State Pharmacopoeia" as they showed acceptable weight variation range. Friability of all brands was less than 1\%. No significant differences were founding disintegration time as they disintegrated within 15 minutes. In case of dissolution profile all brands showed better dissolution time as they released more than $75 \%$ of drug in 45 minute. The hardness of one brand was within the range $40-60 \mathrm{~N}$. The limitation of the potency must be within 95-105\%. All three brands meet this specification. This study suggested that most commercially available clopidogrel tablet in Bangladesh maintain the quality and comply with the USP specifications which are essential for better therapeutic activity of these anti-platelet drug.

Keywords: Clopidogrel; Physicochemical parameters; Potency; Dissolution profile; Cardiovascular

\section{Introduction}

Quality control is a process that is carried out to ensure a desired level of quality in a product or service. It might include whatever actions a business deems necessary to provide for the control and verification of certain characteristics of a product or service [1]. Most often, it involves thoroughly examining and testing the quality of 


\section{Bioequivalence \& Bioavailability International Journal}

products or the results of services. ISO 8402-1986 standard defines that quality is the totality of features and characteristics of a product or service that bears its ability to satisfy stated or implicated needs [2]. Clopidogrel is a routine component of the clinical management of patients after acute coronary syndrome. It has been reported that this drug would reduce rates of major cardiovascular adverse events. It is approved for the reduction of atherosclerotic events in patients with stroke, myocardial infection, cardiovascular disease and acute coronary syndrome. Its action may be related to an adenosine diphosphate (ADP) receptor on platelet cell membranes. It specifically and irreversibly inhibits the platelet P2Y12 subtype of the ADP receptor, which is important in the aggregation of platelets and cross-linking by the protein fibrin 2. As a result, activation of the glycoprotein IIb/IIIa complex, which is involved in platelet activation and stabilization of the platelet aggregate, is also inhibited [3]. The purpose of this study is to evaluate whether the sample brands of clopidogrel tablet maintain the USP specifications and at which level they maintain the quality. This study is also conducted to obtain a brief idea about physico-chemical parameters of those brands and to make a comparison in quality among the sample brands.

\section{Materials and Method}

\section{Recruitment of sample product}

The marketed samples of nine brands (about 20 tablets of each brand) of Clopidogrel tablet were purchased at M.R.P from different Retail pharmacy at Dhaka in Bangladesh. These tablets of nine brands were coded as M1, M2, M3, M4, M5, M6, M7, M8 and M9. The samples were properly checked for their physical appearance, name of manufacturer, batch number, and manufacturing date, expiry date, manufacturing license number, D.A.R. number \& maximum retail price at the time of purchase. There are approximately Twenty eight different brands of clopidogrel are available in Pharma market of Bangladesh (according to BD.DRUGS.COM). Here nine different available brands are chosen from well known pharmaceutical company of Bangladesh [4].

\section{Weight Variation Test}

For each brand, 20 tablets were randomly and weighted individually using an analytical balance (TE214S, sartorius Germany). The average weights were determined using the following formula.

$$
\mathrm{X}=(\mathrm{X} 1+\mathrm{X} 2+\mathrm{X} 3+\ldots \ldots \ldots+\mathrm{Xn}) / 10
$$

Then the percentage weight deviations were determined by using the following formulas [5].

$\%$ of Deviation $(+)=$ (maximum weight- average weight)/average weight $\times 100$.

$\%$ of Deviation $(-)=$ (minimum weight- average weight)/average weight $\times 100$.

\section{Hardness Test}

10 tablets were taken randomly and hardness was measured using automatic Hardness Tester (VEEGO, INDIA). The hardness of tablets, which is the force required to break a tablet in a diametric compression force. If the tablet is too hard, it may not disintegrate in the required period of time or meet the dissolution specification, if it is too soft, it will not withstand the handling during subsequent processing such as coating or packaging and shipping operations [6].

\section{Friability Test}

Friability test should be performed to evaluate the ability of Clopidogrel tablet to withstand abrasion during packaging, handling \& transporting. 20 Clopidogrel tablets were taken randomly \& weighted together. Clopidogrel tablets were then placed into the Roche friabilator \& subjected to $100 \mathrm{rpm}$ for 1 minute at Clopidogrel tablets were re-weighted. This loss of weight indicates the friability of Clopidogrel tablet. Finally the percent of weight of loss was calculated by following way [5]

$$
\text { Loss of } \% \text { of Weight loss }=\frac{(\text { Initialweight }- \text { Finalweight }) * 100}{\text { Initialweight }}
$$

\section{Disintegration Test}

Disintegration test is performed to find out that within how much time the Clopidogrel tablet disintegrates. Disintegration test is very important for all coated \& uncoated tablet because the dissolution rate of drug depends on the disintegration time, which ultimately affect the rate of absorption of drug. About $900 \mathrm{ml}$ buffer solution was taken in both $1000 \mathrm{ml}$ beaker \& then these beakers were placed into the device. One Clopidogrel tablet was placed in each tube of basket rack \& a plastic disk was placed over each tablet \& then the basket rack was accurately positioned into the beaker. The temperature was maintained as $37^{\circ} \mathrm{C}$ i.e. body temperature. The time at which all the Clopidogrel tablets passed through the sieve was the disintegration time \& the average disintegration time were calculated [5]. 


\section{Bioequivalence \& Bioavailability International Journal}

\section{Potency Test}

The potency of Clopidogrel tablet should comply with the specification because very highly potent drug may give toxic effect \& very less potent drug may give subtherapeutic effect. Four tablets of each brand were taken and the average weight was determined. Those 4 tablets of each brand were crushed in mortar and pestle. Amount of powdered tablet containing $10 \mathrm{mg}$ of Clopidogrel drug was determined by calculation. Determined amount of powdered tablet was taken in $100 \mathrm{ml}$ volumetric flask and buffer solution was added up to $100 \mathrm{ml}$. Solution was filtered and $20 \mathrm{ml}$ filtrate was taken in a test tube and was diluted with $100 \mathrm{ml}$ of buffer solution. Absorbance of the sample was determined at $220 \mathrm{~nm}$ wavelength [7].

$\%$ Potency $=\frac{\text { Conc }(\mathrm{mg} \cdot \mathrm{ml}) \times \text { dilutionfactor } \times \text { totalvolume } \times \text { Avg } . w t \times 100}{\text { sampletaken } \times \text { Strenght }}$

\section{Dissolution Test}

About $900 \mathrm{ml}$ of buffer media was filled into $1000 \mathrm{ml}$ beaker of dissolution apparatus. One Clopidogrel tablet was placed into each beaker. $37^{\circ} \mathrm{C}$ i.e. body temperature $\&$ $50 \mathrm{rpm}$ i.e. rotation per minute was adjusted \& then motor was started. $10 \mathrm{ml}$ solution was withdrawn from beaker at $10,15,30,45,60$ minutes interval which was replaced with $10 \mathrm{ml}$ media \& then withdrawn solution was immediately filtered The withdrawn solution of Clopidogrel tablet was 5 times diluted \& absorbance was measured at $220 \mathrm{~nm}$ by using UV spectrophotometer. Finally the percent release of Clopidogrel tablet was determined by following equation [8].

$\%$ of release $=$ drug cont. $(\mathrm{mg}) \times 100 /$ strength $(\mathrm{mg})$

\section{Results and Discussion}

\section{Weight Variation Determination}

Tablet weight is mainly affected by factors such as tooling of the compression machine, head pressure, machine speed and flow properties of the powder. Inconsistent powder or granulate density and particle size distribution are common sources of weight variation during compression. According to USP 29 specification for uniformity of weight which states that tablets weighing $324 \mathrm{mg}$ or more, weights of not more than 2 tablets should not differ from the average weight by more than $5 \%$ The tablets of nine brands undergo this test to assure their uniformity of weight except brand M1, M2, M3 and M4 according to USP specifications [9] (Table 1).

\begin{tabular}{|c|c|c|}
\hline Tablet & Potency (\%) & Weight variation \\
\hline M1 & $100 \pm 5.00$ & $340.65 \pm 7.01$ \\
\hline M2 & $97.3 \pm 5.23$ & $334.4 \pm 11.55$ \\
\hline M3 & $88.35 \pm 8.38$ & $218.2 \pm 5.58$ \\
\hline M4 & $105 \pm 7.07$ & $256.9 \pm 8.54$ \\
\hline M5 & $93 \pm 5.23$ & $217 \pm 3.05$ \\
\hline M6 & $97 \pm 5.29$ & $269.1 \pm 4.51$ \\
\hline M7 & $94.33 \pm 5.97$ & $328.7 \pm 6.01$ \\
\hline M8 & $99.17 \pm 5.02$ & $254.45 \pm 4.98$ \\
\hline M9 & $96.35 \pm 5.50$ & $255 \pm 4.50$ \\
\hline
\end{tabular}

Table 1: potency and weight variation of different brands of clopidogrel tablet collected from local market in Bangladesh.

\section{Hardness Test}

Hardness was monitored using a Automatic Tablet hardness and the result is tabulated at Table 2 and figure 3. Hardness specification according to USP, 2008 is not more than 5-8.0 kg.cm-1 $(1 \mathrm{~kg}=10 \mathrm{~N})$. Only M4 and M8 cross the specification.

\section{Friability Test}

It is the tendency for a tablet to chip, crumble or break following compression. This tendency is normally confined to uncoated tablets and surfaces during handling or subsequent storage. The USP specification for friability test is $1 \%$ [10]. It was monitored that nine different brand of clopidogrel tablets were in accordance with USP guideline (Table 2).

\begin{tabular}{|c|c|c|c|}
\hline Tablets & Hardness(N) & $\begin{array}{c}\text { Friability } \\
\text { (\%) }\end{array}$ & $\begin{array}{c}\text { Disintegration } \\
\text { time (min) }\end{array}$ \\
\hline M1 & $125 \pm 4.95$ & 0.168 & $14.52 \pm 0.21$ \\
\hline M2 & $51.66 \pm 3.03$ & 0.169 & $2.46 \pm 0.13$ \\
\hline M3 & $64.33 \pm 7.34$ & 0.589 & $10.14 \pm 0.34$ \\
\hline M4 & $84 \pm 5.09$ & 0.443 & $1.76 \pm 0.37$ \\
\hline M5 & $36 \pm 2.44$ & 0.392 & $1.56 \pm 0.52$ \\
\hline M6 & $50.67 \pm 2.05$ & 0.318 & $1.06 \pm 0.03$ \\
\hline M7 & $45 \pm 4.98$ & 0.262 & $3.88 \pm 0.15$ \\
\hline M8 & $102 \pm 3.74$ & 0.452 & $2.68 \pm 0.14$ \\
\hline M9 & $79 \pm 7.77$ & 0.280 & $3.77 \pm 0.25$ \\
\hline
\end{tabular}

Table 2: Average drug release (\%) of nine different brands of clopidogrel tablets.

\section{Disintegration Test}

Disintegration tests are performed as per the pharmacopoeia standards. Disintegration is a measure of the quality of the oral dosage form like tablets and capsule pharmacopoeia like the USP, BP, IP etc. each have their 
own set of standards and specify disintegration tests of their own. The disintegration test is performed to find out the time it takes for a solid oral dosage form like a tablet or capsule to completely disintegrate. The time of disintegration is a measure of the quality. This is because, for example, if the disintegration time is too high; it means that the tablet is too highly compressed or the capsule shell gelatin is not of pharmacopoeia quality or it may imply several other reasons. And also if the disintegration time is not uniform in a set of samples being analyzed, it indicates batch inconsistency and lack of batch uniformity. According to USP, 2013 the specification of disintegration time requirements 5 to 30 minutes. All the tablets that have been tested are within the limit [11] (Table 2).

\section{Potency Test}

Potency of all brands was found within 95.34-
$103.65 \%$.USP specification for the drugs are equivalent to not less than $95.0 \%$ \& not more than $105.0 \%$. Six brands are within the limit of potency according to the USP specification (Table 1 ).

\section{Dissolution Test}

Dissolution is a test used by the Pharmaceutical industry to characterize the dissolution properties of the active drug, the active drug's release and the dissolution from a dosage formulation. Dissolution testing is used to formulate the drug dosage form and to develop quality control specifications for its manufacturing process. The USP specification of Clopidogrel is not less than $75 \%$ of the labeled amount dissolved in 45 minutes [12]. It is seen from the result that all brand of Clopidogrel tablets meet the specification (Table 3).

\begin{tabular}{|c|c|c|c|c|c|c|c|c|c|}
\hline $\begin{array}{c}\text { Time } \\
\text { (min) }\end{array}$ & \multicolumn{10}{|c|}{ \% of Drug Release } \\
\hline & M1 & M2 & M3 & M4 & M5 & M6 & M7 & M8 & M9 \\
\hline $\mathbf{0}$ & $\mathbf{0}$ & $\mathbf{0}$ & $\mathbf{0}$ & $\mathbf{0}$ & $\mathbf{0}$ & $\mathbf{0}$ & $\mathbf{0}$ & $\mathbf{0}$ & $\mathbf{0}$ \\
\hline $\mathbf{5}$ & $30.92 \pm 0.15$ & $34.14 \pm 0.39$ & $30.92 \pm 0.25$ & $26.34 \pm 0.45$ & $26.34 \pm 0.23$ & $24.31 \pm 0.14$ & $20.89 \pm 0.32$ & $24.18 \pm 0.23$ & $21.92 \pm 0.68$ \\
\hline $\mathbf{1 5}$ & $49.67 \pm 0.12$ & $47.67 \pm 0.13$ & $46.45 \pm 0.21$ & $39.32 \pm 0.43$ & $39.32 \pm 0.35$ & $38.32 \pm 0.15$ & $40.82 \pm 0.64$ & $42.50 \pm 0.65$ & $41.37 \pm 0.55$ \\
\hline $\mathbf{3 0}$ & $55.73 \pm 0.42$ & $61.81 \pm 0.48$ & $53.28 \pm 0.25$ & $60.56 \pm 0.46$ & $60.56 \pm 0.45$ & $63.69 \pm 0.55$ & $66.12 \pm 0.26$ & $55.67 \pm 0.78$ & $61.72 \pm 0.44$ \\
\hline $\mathbf{4 5}$ & $72.01 \pm 0.67$ & $75.97 \pm 0.42$ & $71.31 \pm 0.35$ & $83.12 \pm 0.55$ & $83.12 \pm 0.46$ & $82.33 \pm 0.65$ & $83.64 \pm 0.75$ & $79.86 \pm 0.67$ & $77.50 \pm 0.65$ \\
\hline $\mathbf{6 0}$ & $96.17 \pm 0.53$ & $98.57 \pm 0.49$ & $96.06 \pm 0.54$ & $92.46 \pm 0.43$ & $92.46 \pm 0.21$ & $100.47 \pm 0.54$ & $96.74 \pm 0.45$ & $97.11 \pm 0.65$ & $97.03 \pm 0.54$ \\
\hline
\end{tabular}

\section{potency $\%$}

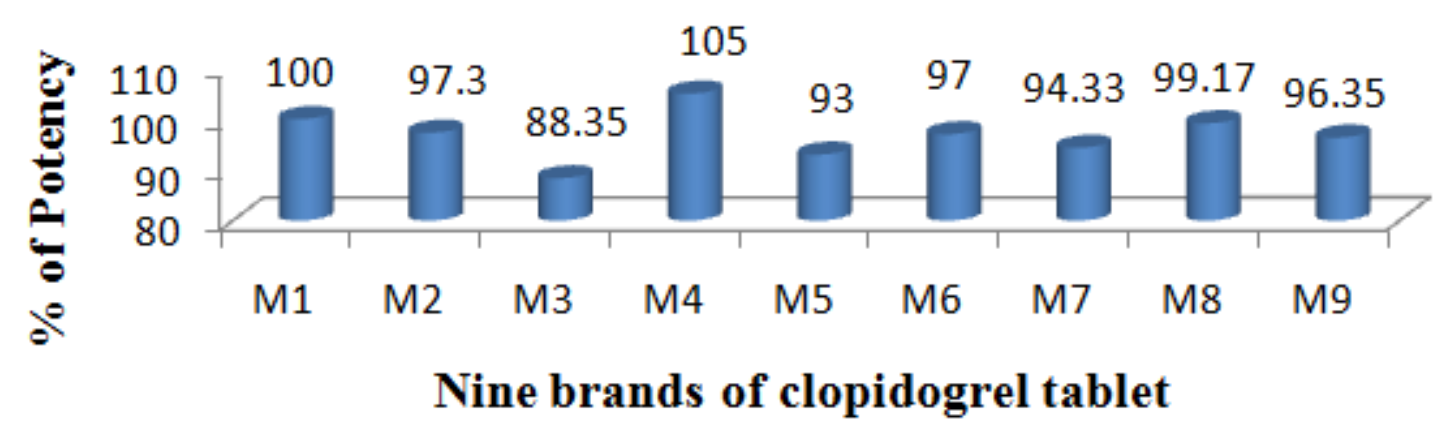

Figure1: Determination of potency of nine brands of clopidogrel tablet. 


\section{Weight variation}

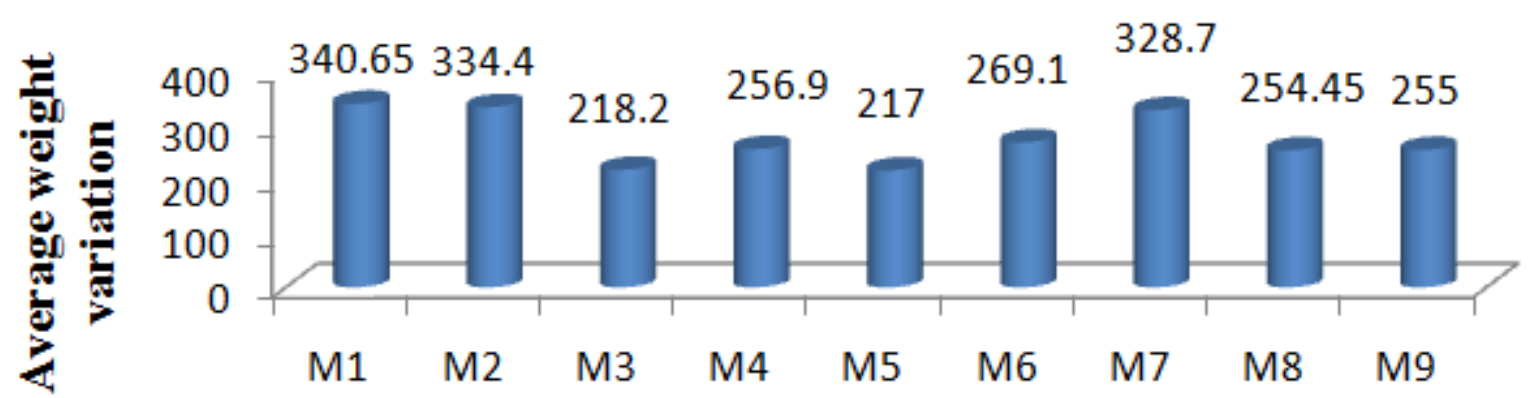

Nine brands of clopidogrel tablet

Figure 2: Average weight variation of nine brands of Clopidogrel tablet.

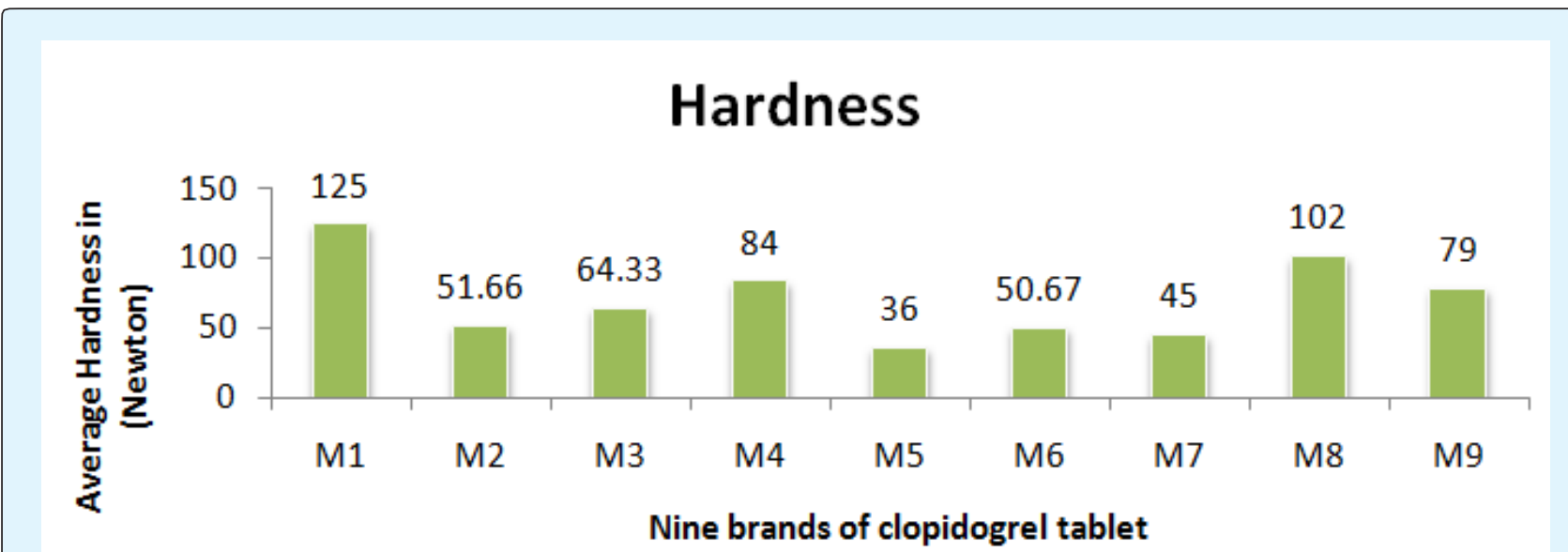

Figure 3: Average hardness of nine brands of Clopidogrel tablet.

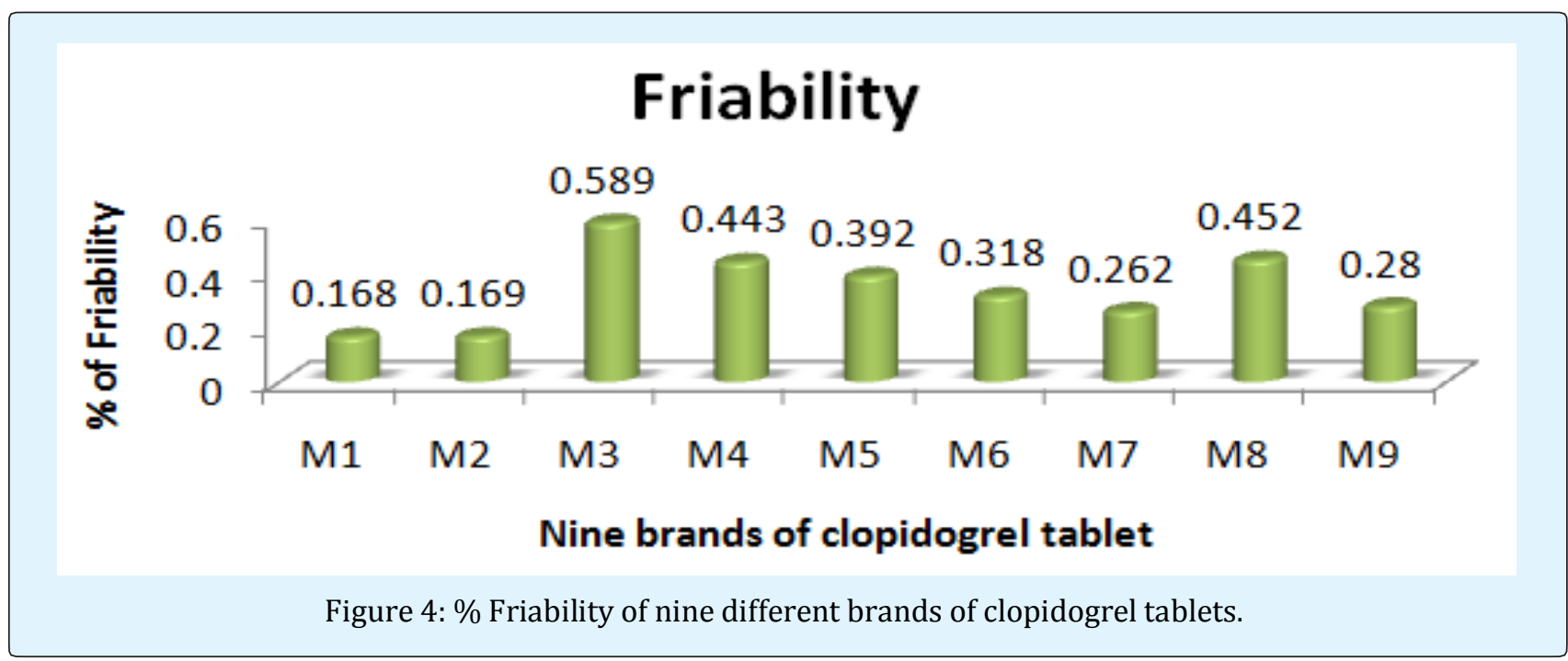




\section{Disintegration}

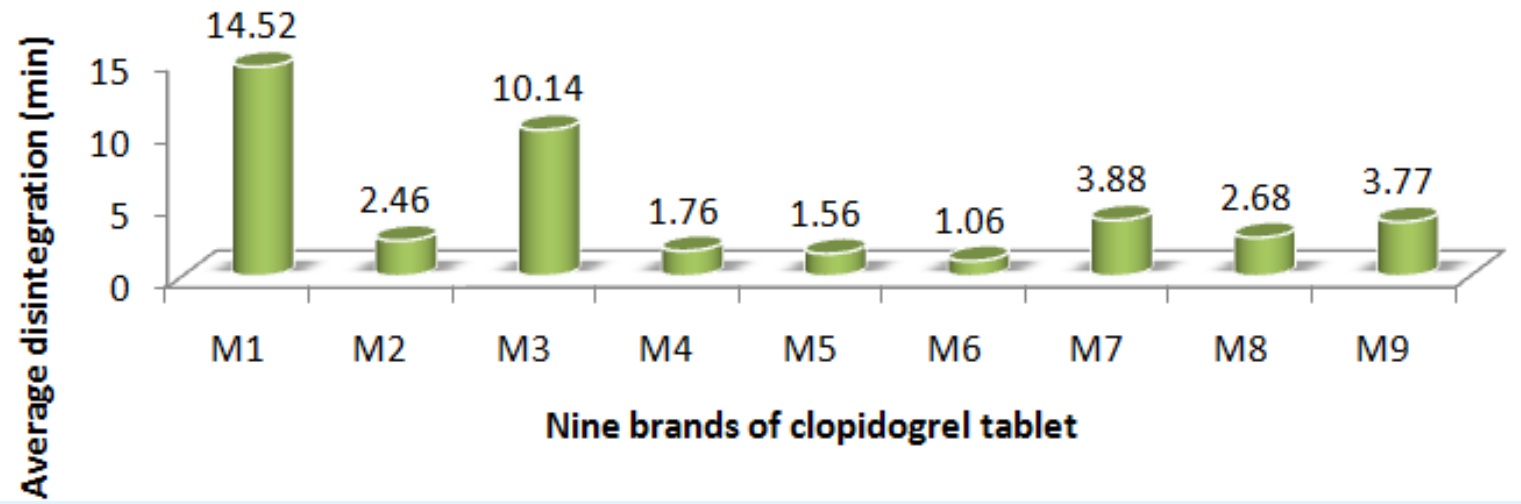

Figure 5: Disintegration time of nine different brands of clopidogrel tablets

\begin{tabular}{|c|c|c|c|c|c|c|c|c|c|}
\hline $\begin{array}{c}\text { Time } \\
\text { (min) }\end{array}$ & \multicolumn{9}{|c|}{ \% of Drug Release } \\
\hline & M1 & M2 & M3 & M4 & M5 & M6 & M7 & M8 & M9 \\
\hline $\mathbf{0}$ & $\mathbf{0}$ & $\mathbf{0}$ & $\mathbf{0}$ & $\mathbf{0}$ & $\mathbf{0}$ & $\mathbf{0}$ & $\mathbf{0}$ & $\mathbf{0}$ & $\mathbf{0}$ \\
\hline $\mathbf{5}$ & $30.92 \pm 0.15$ & $34.14 \pm 0.39$ & $30.92 \pm 0.25$ & $26.34 \pm 0.45$ & $26.34 \pm 0.23$ & $24.31 \pm 0.14$ & $20.89 \pm 0.32$ & $24.18 \pm 0.23$ & $21.92 \pm 0.68$ \\
\hline $\mathbf{1 5}$ & $49.67 \pm 0.12$ & $47.67 \pm 0.13$ & $46.45 \pm 0.21$ & $39.32 \pm 0.43$ & $39.32 \pm 0.35$ & $38.32 \pm 0.15$ & $40.82 \pm 0.64$ & $42.50 \pm 0.65$ & $41.37 \pm 0.55$ \\
\hline $\mathbf{3 0}$ & $55.73 \pm 0.42$ & $61.81 \pm 0.48$ & $53.28 \pm 0.25$ & $60.56 \pm 0.46$ & $60.56 \pm 0.45$ & $63.69 \pm 0.55$ & $66.12 \pm 0.26$ & $55.67 \pm 0.78$ & $61.72 \pm 0.44$ \\
\hline $\mathbf{4 5}$ & $72.01 \pm 0.67$ & $75.97 \pm 0.42$ & $71.31 \pm 0.35$ & $83.12 \pm 0.55$ & $83.12 \pm 0.46$ & $82.33 \pm 0.65$ & $83.64 \pm 0.75$ & $79.86 \pm 0.67$ & $77.50 \pm 0.65$ \\
\hline $\mathbf{6 0}$ & $96.17 \pm 0.53$ & $98.57 \pm 0.49$ & $96.06 \pm 0.54$ & $92.46 \pm 0.43$ & $92.46 \pm 0.21$ & $100.47 \pm 0.54$ & $96.74 \pm 0.45$ & $97.11 \pm 0.65$ & $97.03 \pm 0.54$ \\
\hline
\end{tabular}

Table 3: Average drug release (\%) of nine different brands of clopidogrel tablets.

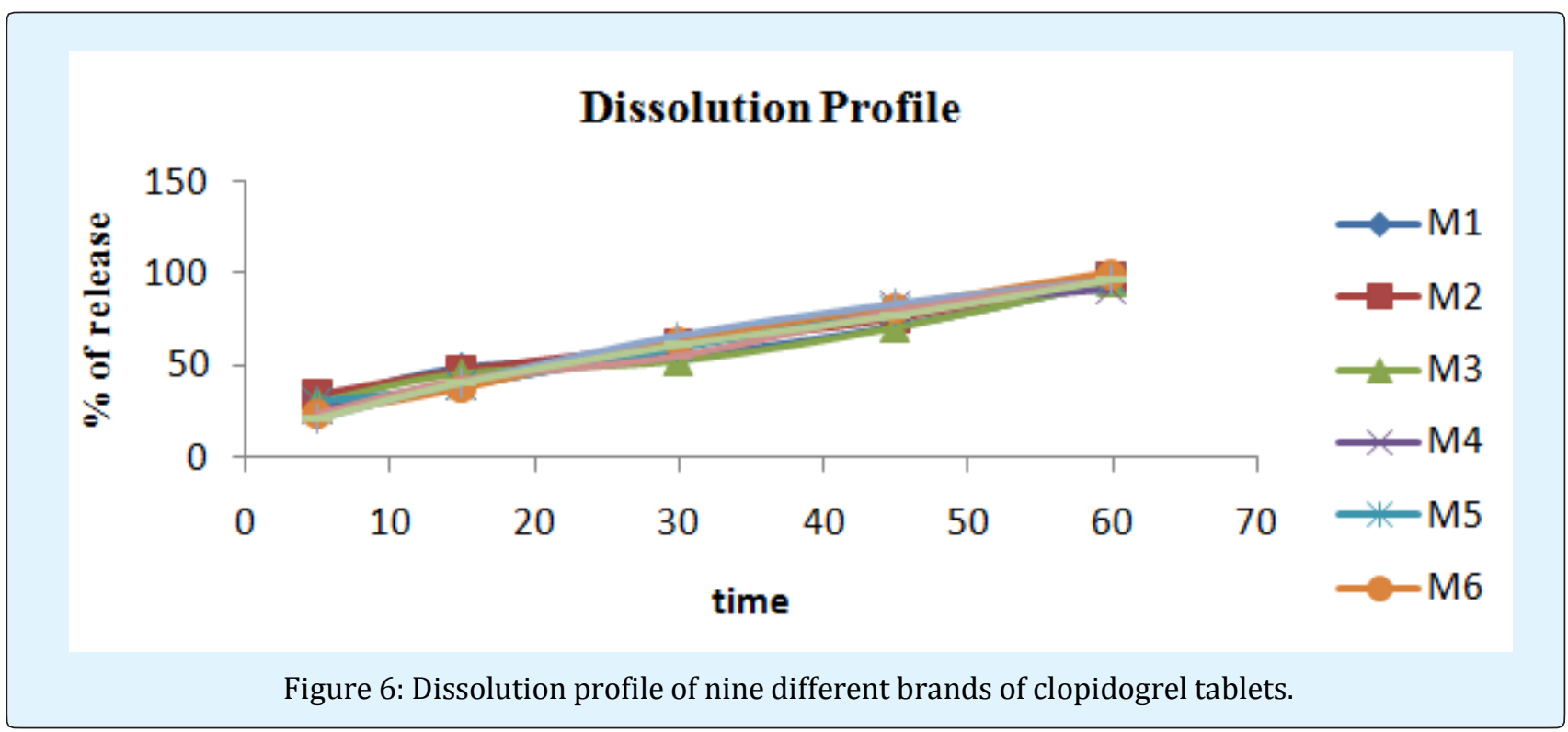

Kanij ND, et al. Comparative In Vitro Quality Evaluation of Some Clopidogrel Tablets, 


\section{Bioequivalence \& Bioavailability International Journal}

\section{Conclusion}

Overall quality of a pharmaceutical product depends on control of impurities, presence of therapeutic agent that developed potency, safety and efficacy of the drug. A quality product gives not only better therapeutic efficacy but also gives consumer satisfaction and increases its market demand. In the current industrial practice, to compare with the multi brand generic molecules and to provide enough therapeutic activity of the dosage form, in-vitro tests play a significant role. In this study we discussed about some quality test such as weight variation, hardness, friability, disintegration time, potency and dissolution test for clopidogrel tablet. Clopidogrel tested tablet have uniform weight and also sufficient physical stability to maintain physical integrity over time and they will also be capable of withstanding the stiffness of mechanical shocks confrontation in its production, packaging, shipping and dispensing.

\section{References}

1. Hasan A, Dewan SAR, Ahamed SK, Kai MM (2013) Quality control studies on cetirizine hydrochloride tablets available in Bangladesh drug market. International Journal of Pharmacy and Biological Sciences 3(1): 349-354.

2. Nasrin N, Asaduzzaman M, Mowla R, Rizwan F, Alam A (2011) A comparative study of physical parameters of selected ketorolac tromethamine tablets available in the pharma market of Bangladesh. Journal of applied phramceutical Sciences 1(8): 101-103.

3. Yarkala S, Sivakumar A, Sameer G (2012) PhysicoChemical Studies on Stability of Clopidogrel Tablet Formulations. International Journal of Pharmaceutical and Biological Science 3(4): 433-439.

4. Goodman \& Gilman's Pharmacological basis of therapeutics. In Goodman \& Gilman, BruntonL,
Editors. Blood coagulation and anticoagulants, Fibrinolytic and antiplatelet drugs. Bruce Chabner. Bjorn Knollman, 12 ${ }^{\text {th }}$ (Edn.), Pp: 849-876.

5. Lachman L (1976) Pharmaceutical dosage form. In Lachman L, Lieberman HA (Eds.). The Theory and Practice of Industrial Pharmacy. Lea \& Febiger, Verghese Publishing House Pp: 293-373.

6. Gupta KA (2010) Introduction to Pharmaceutics-I. Cbs Publishers \& Distributors, New Delhi (India), Pp: 344-398.

7. Eric RB, Wei CL, Dominick JA (2011) ClopidogrelDrug Interactions. Journal of the American College of Cardiology 57(11): 18-23.

8. Katzung. Basic \& clinical Pharmacology. In katzung, Katzung B, Editors. Drugs used in disorders of coagulations, Mc Grawhill. Lange, 12 $2^{\text {th }}$ (Edn.), pp: 601618.

9. Kishore N, Singh A, Reddy N (2013) Formulation and Evaluavation of Clopidogrel Bisulfate Immediate Release Tablets. International Journal of Life Sciences 1(1): 11-18.

10. Nushrat SA, Nasreen W, Deepa KN (2017) In vitro comparative study of quality control parameter of some brand of ketorolac tablets available in Bangladesh. World journal of pharmacy and pharmaceutical science 6(8): 146-155.

11. Kumar K, Vijayakumar K, Reddy N (2013) Clopidogrel an Overview. International journal of Pharmacology science 3(1): 1-7.

12. Ralston S (2010) Cardiovascular disease. Churchill living stone, Elsevier Pp: 592-640. 